\title{
Water uptake by biomass burning aerosol at sub- and supersaturated conditions: closure studies and implications for the role of organics
}

\author{
U. Dusek ${ }^{1, *}$, G. P. Frank ${ }^{1, * * * * *}$, A. Massling ${ }^{2, * * *}$, K. Zeromskiene $^{2, * * * * *}$, Y. Iinuma ${ }^{2}$, O. Schmid ${ }^{1, * *}$, G. Helas ${ }^{1}$, \\ T. Hennig ${ }^{2, * * * *}$, A. Wiedensohler ${ }^{2}$, and M. O. Andreae ${ }^{1}$ \\ ${ }^{1}$ Max Planck Institute for Chemistry, Biogeochemistry Department, Mainz, Germany \\ ${ }^{2}$ Leibniz-Institute for Tropospheric Research, Leipzig, Germany \\ *now at: Institute for Marine and Atmospheric Sciences Utrecht, Utrecht University, Utrecht, The Netherlands \\ ** now at: Comprehensive Pneumology Center, Institute of Lung Biology and Disease, Helmholtz Zentrum München, \\ Germany \\ **** now at: National Environmental Research Institute, Aarhus University, Roskilde, Denmark \\ **** now at: Department for Applied Environmental Science (ITM), Stockholm University, Stockholm, Sweden \\ ****** now at: Dillon Consulting Ltd., Toronto, Canada \\ ******* now at: Department of Physics, Lund University, Lund, Sweden
}

Received: 4 November 2010 - Published in Atmos. Chem. Phys. Discuss.: 7 December 2010

Revised: 21 July 2011 - Accepted: 29 July 2011 - Published: 16 September 2011

\begin{abstract}
We investigate the CCN activity of freshly emitted biomass burning particles and their hygroscopic growth at a relative humidity $(\mathrm{RH})$ of $85 \%$. The particles were produced in the Mainz combustion laboratory by controlled burning of various wood types. The water uptake at sub- and supersaturations is parameterized by the hygroscopicity parameter, $\kappa$ (c.f. Petters and Kreidenweis, 2007). For the wood burns, $\kappa$ is low, generally around 0.06 . The main emphasis of this study is a comparison of $\kappa$ derived from measurements at sub- and supersaturated conditions $\left(\kappa_{\mathrm{G}}\right.$ and $\left.\kappa_{\mathrm{CCN}}\right)$, in order to see whether the water uptake at $85 \% \mathrm{RH}$ can predict the CCN properties of the biomass burning particles. Differences in $\kappa_{\mathrm{G}}$ and $\kappa_{\mathrm{CCN}}$ can arise through solution nonidealities, the presence of slightly soluble or surface active compounds, or non-spherical particle shape. We find that $\kappa_{\mathrm{G}}$ and $\kappa_{\mathrm{CCN}}$ agree within experimental uncertainties (of around $30 \%$ ) for particle sizes of 100 and $150 \mathrm{~nm}$; only for $50 \mathrm{~nm}$ particles is $\kappa_{\mathrm{CCN}}$ larger than $\kappa_{\mathrm{G}}$ by a factor of 2 . The magnitude of this difference and its dependence on particle size is consistent with the presence of surface active organic compounds. These compounds mainly facilitate the $\mathrm{CCN}$ activation of small particles, which form the most concentrated
\end{abstract}

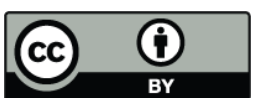

Correspondence to: U. Dusek (u.dusek@uu.nl) solution droplets at the point of activation. The $50 \mathrm{~nm}$ particles, however, are only activated at supersaturations higher than $1 \%$ and are therefore of minor importance as $\mathrm{CCN}$ in ambient clouds. By comparison with the actual chemical composition of the biomass burning particles, we estimate that the hygroscopicity of the water-soluble organic carbon (WSOC) fraction can be represented by a $\kappa_{\mathrm{WSOC}}$ value of approximately 0.2 . The effective hygroscopicity of a typical wood burning particle can therefore be represented by a linear mixture of an inorganic component with $\kappa \cong 0.6$, a WSOC component with $\kappa \cong 0.2$, and an insoluble component with $\kappa=0$.

\section{Introduction}

Both, CCN properties and hygroscopic growth of aerosols are determined by the amount and nature of the soluble and insoluble materials contained in the particles. It is therefore reasonable to assume a relationship between the hygroscopic growth at subsaturated conditions and the critical supersaturation of droplet activation. This has been the motivation for developing models to predict critical supersaturations based on aerosol hygroscopic growth factors measured at subsaturated conditions (e.g., Brechtel and Kreidenweis, 2000a, b; Rissler et al., 2004; Kreidenweis et al., 2005; Koehler et

Published by Copernicus Publications on behalf of the European Geosciences Union. 
al., 2006; Petters and Kreidenweis, 2007; Wex et al., 2008a; Ziese et al., 2008, Ervens at al., 2007). Similar strategies have been used for hygroscopicity/CCN closure studies on ambient aerosols (e.g., Covert et al., 1998; Dusek et al., 2003; Gasparini et al., 2006; Vestin et al., 2007; Mochida et al., 2006; Svenningsson et al., 1997), on jet engine exhaust (Gysel et al., 2003; Hitzenberger et al., 2003), on secondary organic aerosol (Wex et al., 2009; Petters et al., 2009b), and on laboratory-generated coated soot particles (Henning et al., 2010, Snider et al., 2010, Stratmann et al., 2010). In addition, there has been one study comparing hygroscopic growth and $\mathrm{CCN}$ activation of biomass burning aerosol (Petters et al., 2009a). These closure studies have had various degrees of success, but in principle it can be concluded that predicting $\mathrm{CCN}$ properties based on hygroscopic growth factors is similarly successful as predicting $\mathrm{CCN}$ properties based on chemical information.

One important reason for a potential failure of the extrapolation from hygroscopic growth measurements to $\mathrm{CCN}$ properties is the presence of slightly soluble (SS) or surfactant (SA) organic compounds in the aerosol. These organic compounds influence in different manner the water uptake at suband at supersaturated conditions. SS substances contribute little to the water uptake at subsaturated conditions, because they do not fully dissolve even at high relative humidities $(\mathrm{RH})$ in the concentrated solution droplets and remain as a solid core surrounded by a solution in which the SS substance is saturated. At RH close to $100 \%$ the particles contain much more water, and more of the SS substances go into solution until all SS material is dissolved. Therefore their contribution to the water uptake becomes significant at supersaturated conditions because more of the SS material dissolves in the diluted droplets (e.g., Dusek et al., 2003). Changes in surface tension due to SA substances barely affect the water uptake at subsaturated conditions. However, a decrease in droplet surface tension near the critical supersaturation greatly facilitates CCN activation (Facchini et al., 1999; Wex et al., 2008a). In both cases the particles are more easily activated to cloud droplets than would be expected based on the water uptake at RH below $100 \%$.

Little is known about the importance of SS and SA substances for $\mathrm{CCN}$ activation in the atmosphere. In some environments, the comparison of measured $\mathrm{CCN}$ concentrations with $\mathrm{CCN}$ concentrations predicted from hygroscopic growth factors has suggested that the influence of SA and SS substances is limited (e.g., Dusek et al., 2003; Gasparini et al., 2006; Ervens et al., 2005; Andreae and Rosenfeld, 2008). However, where the aerosol composition is dominated by organic material, there is an indication that compounds of limited solubility can cause discrepancies in the water uptake at sub- and supersaturated conditions (Mircea et al., 2005; Mochida et al., 2006; Chang et al., 2007).

In the present study we aim to investigate the possible presence of SA and SS substances in fresh biomass burning emissions and their importance for $\mathrm{CCN}$ activation. We identify such substances indirectly, by investigating possible discrepancies in the water uptake at sub- and supersaturated conditions. Such a comparison of water uptake requires precise information on hygroscopic growth and critical supersaturations of the aerosol particles. This study therefore greatly benefits from size-resolved CCN spectra (Frank et al., 2006) measured at the same dry particle diameters $\left(d_{\mathrm{p}}\right)$ as the corresponding hygroscopic growth factors $(\mathrm{GF})$.

\section{Experimental methods}

The properties of pyrogenic aerosols were studied as part of the project EFEU (Wurzler et al., 2001) in the combustion laboratory in Mainz, which is described in detail by Iinuma et al. (2007). The laboratory fires were sustained on a fuel bed housed in a container open to the ambient air. Through an exhaust stack, the smoke was drawn into a continuous-flow mixing chamber (residence time approximately $7 \mathrm{~min}$ ), from which the aerosol was sampled. The duration of each experiment was approximately one hour and included both flaming and smoldering conditions, with typical excess $\mathrm{CO} / \mathrm{CO}_{2}$ ratios between 3 and $15 \%$.

Size-resolved CCN spectra were measured by using a differential mobility analyzer (DMA) upstream of a static thermal gradient CCN counter (Frank et al., 2007). The DMA selected particles within a narrow size range (aerosol to sheath flow ratio of $1 / 10$ ) at a relative humidity of less than $10 \%$. These particles were then passed to the $\mathrm{CCN}$ counter and a condensation particle counter (CPC; TSI 3762) measuring in parallel. While the $\mathrm{CCN}$ counter measured the particles that were activated as $\mathrm{CCN}$ at a certain supersaturation, $S$, the CPC measured the total particle number concentration $(\mathrm{CN})$. The fraction of activated particles (defined as $\mathrm{CCN} / \mathrm{CN}$ ) was calculated for each supersaturation $(S)$ and dry particle diameter $\left(d_{\mathrm{p}}\right)$, after correction for multiply charged particles (Frank et al., 2006; Rose et al., 2008). A full CCN scan (4 diameters at 5 values of $S$ each) took approximately $15 \mathrm{~min}$. Due to the mixing chamber the aerosol was stable for a scan at a single diameter and usually reasonably stable during a full scan. Particle size distributions used for multiple charge corrections were measured using an SMPS system (Zeromskiene, 2005).

For chemical analysis, particles were sampled using a Berner-type cascade impactor (Berner and Lürzer, 1987). The deposited material on each stage was quantitatively analyzed with respect to inorganic ions, apparent elemental carbon $\left(\mathrm{EC}_{\mathrm{a}}\right.$; Andreae and Gelencsér, 2006), organic carbon (OC), water soluble organic carbon (WSOC), and water insoluble organic carbon (WIOC, calculated as OC minus WSOC). The methods used were ion chromatography for inorganic ions, a thermographic method for OC and $\mathrm{EC}_{\mathrm{a}}$ (VDI, 1999), and a Shimadzu TOC analyzer for WSOC. A more detailed description of the impactor measurements can be found in Iinuma et al. (2007). 
Measurements of particle hygroscopic growth were done using a Hygroscopicity-Tandem Differential Mobility Analyzer (H-TDMA). The H-TDMA consists of two Differential Mobility Analyzers (DMA1 and DMA2) separated by a conditioning unit where the particles are exposed to an elevated relative humidity, $\mathrm{RH}=85 \%$. DMA1 selects a nearly monodisperse fraction of the aerosol, while DMA2 scans the humidified size distribution after the conditioning unit. The raw humidified size distribution is inverted using an algorithm by Voutilainen et al. (1999) and the hygroscopic growth factor (GF) is defined as the ratio of the median wet particle diameter determined by DMA2 and the dry particle diameter $\left(d_{\mathrm{p}}\right)$ determined by DMA1. Usually 2-3 growth factor measurements were averaged for one biomass burning experiment.

\section{Data analysis methods}

Discrepancies in the water uptake at subsaturated and supersaturated conditions can give an indication for the presence of SA and/or SS material. An efficient tool for detecting such inconsistencies is the $\kappa$ parameterization of Petters and Kreidenweis (2007). The water uptake of a particle is represented by a single parameter, $\kappa$ that can be used as a representation of solute hygroscopicity in the Köhler equation. Other parameterizations include so-called equivalent soluble volume fractions (e.g., Swietlicki et al., 1999; Lehmann et al., 2005; and references therein) or ion fractions (e.g., Rissler et al., 2004). All these parameterizations are equivalent and the different parameters can easily be converted. Because of the widespread use of the $\kappa$ parameterization we will express our results in terms of $\kappa$. Typical $\kappa$ values for well-known aerosol constituents are $\kappa \sim 0.6$ for ammonium sulfate, $\sim 1.2$ for sodium chloride and $\sim 0.2$ for levoglucosan.

In this work, we calculate $\kappa$ both from measured growth factors $\left(\kappa_{\mathrm{G}}\right)$ and $\mathrm{CCN}$ spectra $\left(\kappa_{\mathrm{CCN}}\right)$. If these volume fractions show only small differences typical of non-idealities of aerosol constituents, this indicates that there is no large influence of SS and SA substances. If $\kappa_{\mathrm{CCN}}$ is substantially larger than $\kappa_{\mathrm{G}}$, SS or SA substances are potentially affecting the activation behavior of the particles.

\subsection{Calculating $\kappa_{\mathrm{G}}$ and $\kappa_{\mathrm{CCN}}$}

$\kappa_{\mathrm{CCN}}$ is calculated using Eq. (6) in Petters and Kreidenweis (2007)

$S(d)=\frac{d^{3}-d_{\mathrm{dry}}^{3}}{d^{3}-d_{\mathrm{dry}}^{3}(1-\kappa)} \exp \left(\frac{A}{d}\right)$,

where $S$ is the saturation ratio, $d$ is the ambient particle diameter, $d_{\text {dry }}$ is the dry particle diameter and

$A=\frac{4 \sigma \cdot M_{\mathrm{W}}}{R \cdot T \cdot \rho_{\mathrm{W}}}$ where $\sigma$ is the surface tension of the solution, $R$ is the universal gas constant, $T$ is the absolute ambient temperature, $M_{\mathrm{w}}$ denotes molecular mass, and $\rho_{\mathrm{w}}$ the density of water, respectively. For all calculations in this manuscript the surface tension of water is used for $\sigma_{\mathrm{s}}$ and $T=293 \mathrm{~K}$.

The critical supersaturation $S_{\mathrm{c}}$ is calculated from the maximum of the Köhler curve with respect to $d$

$S_{\mathrm{c}}=\max _{d}(s)-1$

and is therefore only a function of $\kappa$. Assuming that $S_{\mathrm{c}}^{\mathrm{m}}$ is the experimentally determined critical supersaturation of an actual particle with unknown composition, $\kappa_{\mathrm{CCN}}$ for this particle can be calculated by numerically solving the following equation for $\kappa$ :

$S_{\mathrm{c}}(\kappa)=S_{\mathrm{c}}^{\mathrm{m}}$.

$\kappa_{\mathrm{G}}$ is estimated according to Eq. (11) in Petters and Kreidenweis (2007)

$\frac{\mathrm{RH}}{\exp \left(\frac{A}{d_{\mathrm{dry} \cdot \mathrm{GF}}}\right)}=\frac{\mathrm{GF}^{3}-1}{\mathrm{GF}^{3}-(1-\kappa)}$,

where GF is the hygroscopic growth factor and $\mathrm{RH}$ is the relative humidity at which it was measured, in our case 0.85 .

\subsection{Estimating $\kappa_{\mathrm{G}}$ and $\kappa_{\mathrm{CCN}}$ from measured growth distributions and $\mathrm{CCN}$ spectra}

Equations (1-5) can be used for calculating $\kappa$ of monodisperse particles with well defined GF and $S_{\mathrm{c}}$. However, for laboratory-generated biomass burning aerosol as considered here, particles of the same size do not necessarily have the same chemical composition and shape. As a consequence, biomass burning particles of a certain size class show hygroscopic growth factors with a certain spread around a mean, and gradual $\mathrm{CCN}$ activation spectra that are not simply represented by step functions. For the wood burning particles, the growth factor distributions had a single mode. However, the spread of the growth factor distribution and the gradual CCN activation spectra cause some uncertainties in the derivation of the appropriate $\kappa$.

Figure 1 shows a typical example of humidified size distributions of particles with dry diameters of $d_{\mathrm{p}}=50,100$, and $150 \mathrm{~nm}$ as measured by the H-TDMA at $\mathrm{RH}=85 \%$. These distributions are generated from the measured data by an inversion routine that fits the inverted spectra with a continuous function (Voutilainen et al., 1999). Usually, monomodal growth distributions are summarized by a single diameter growth factor GF, defined as the modal diameter of the wet size distribution divided by the centroid dry diameter. The hygroscopic growth factor and the soluble volume fraction $(\varepsilon)$ are nearly linearly related over a small GF range from 1.04 to 1.1 , which is typical for this study. Therefore, the shape of the growth factor distribution (after correction for the DMA1 transfer function) roughly corresponds to the 


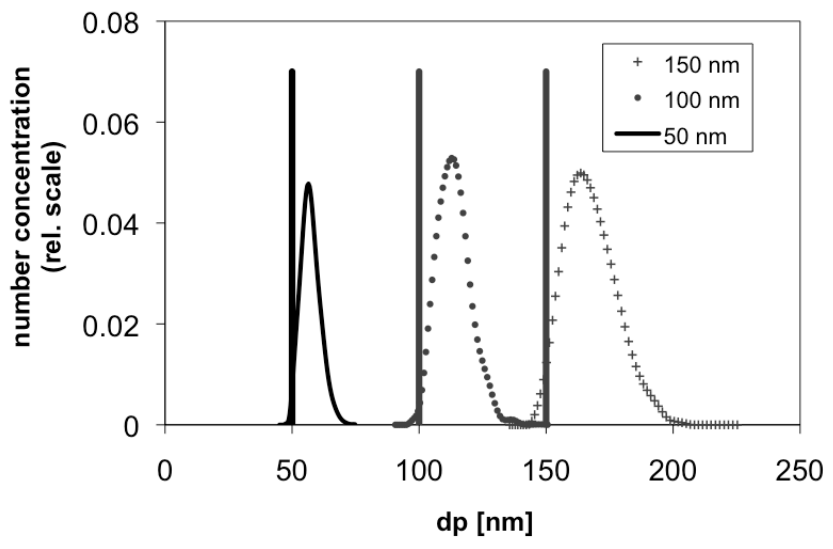

Fig. 1. Typical humidified size distributions as measured by the H-TDMA for particles with nominal dry diameters of $d_{\mathrm{p}}=50 \mathrm{~nm}$, $100 \mathrm{~nm}$, and $150 \mathrm{~nm}$ (vertical lines).

shape of the soluble volume distribution. The distributions of the wood burning particles are fairly (though not completely) symmetrical and can be quite well approximated by a normal distribution. As a consequence the mode, mean, and median diameter are close to each other. Since $\kappa$ is directly proportional to $\varepsilon$, the experimentally determined GF of the single mode can therefore be used to calculate a $\kappa_{\mathrm{G}}$ that is representative for the mean soluble volume of the selected size fraction.

The derivation of $\kappa_{\mathrm{CCN}}$ from actual $\mathrm{CCN}$ spectra is not straightforward, as demonstrated on a representative example shown in Fig. 2a. In this study, the CCN spectra have to be linearly interpolated to find $S_{\mathrm{c}}^{\mathrm{m}}$, because a more complicated fitting function, such as an error function, is often poorly constrained, due to the small number of data points per CCN spectrum. For a certain particle size fraction, a typical median supersaturation, $S_{\mathrm{c}}^{\mathrm{m}}$, is usually derived by finding the supersaturation where $50 \%$ of the particles are activated $(\mathrm{CCN} / \mathrm{CN}$ ratio $=0.5)$. This supersaturation can subsequently be converted to $\kappa\left(S_{\mathrm{c}}^{\mathrm{m}}\right)$ by use of Eqs. (1-4). However, unlike $\mathrm{GF}, S_{\mathrm{c}}$ is not linearly related to the soluble volume (and therefore $\kappa$ ) of the particle, and a linear interpolation of the CCN spectrum is therefore a poor approximation for $S_{\mathrm{c}}^{\mathrm{m}}$. A different way of deriving a representative $\kappa$ from the CCN spectra is to convert each $S$ in the spectrum to the corresponding $\kappa$ value at the selected $d_{\mathrm{p}}$, and to plot $\mathrm{CCN} / \mathrm{CN}$ values as a function of $\kappa$ (see Fig. 2b). Then $\kappa_{\mathrm{CCN}}$ can be calculated as the value at $\mathrm{CCN} / \mathrm{CN}=0.5$, as indicated by the dotted vertical line in Fig. 2b. As long as the soluble volume is roughly normally distributed (as can be verified from the GF distribution) a linear interpolation is a good approximation of the median $\kappa$. Therefore, the method illustrated in Fig. $2 \mathrm{~b}$ is used to derive $\kappa_{\mathrm{CCN}}$. This example illustrates to which extent errors related to the interpolation methods of the $\mathrm{CCN}$ spectra can affect the comparison of $\kappa_{\mathrm{CCN}}$ and $\kappa_{\mathrm{G}}$. If the growth factor distribution is more strongly asymmetric, then the mode

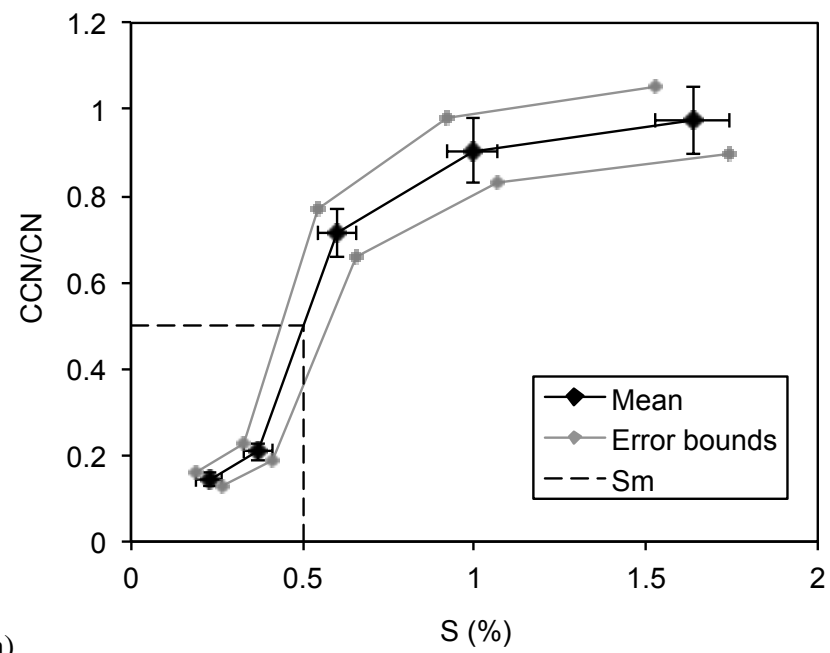

(a)

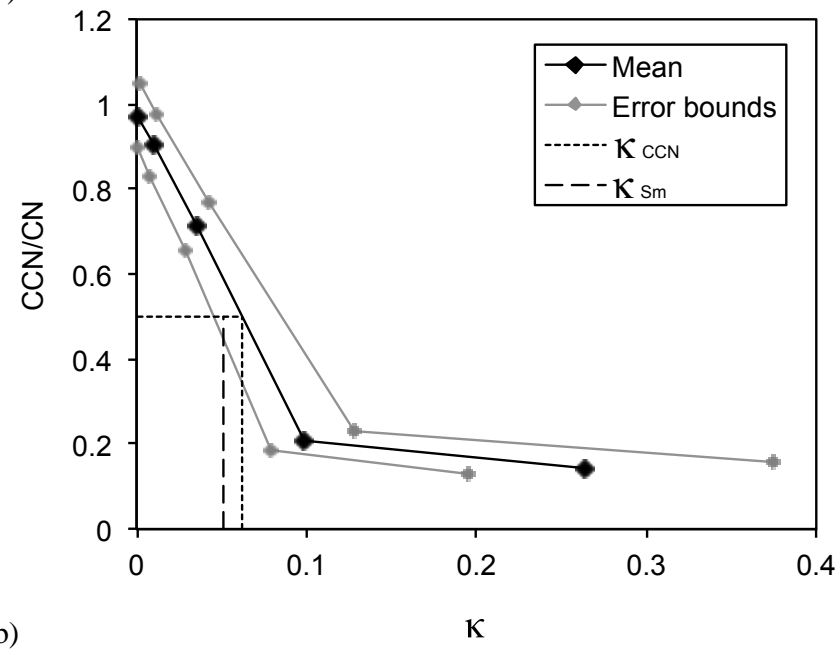

Fig. 2. The derivation of $\kappa_{\mathrm{CCN}}$ using $100 \mathrm{~nm}$ oak wood smoke particles as an example. (a) Average CCN spectrum from experiment $14 \mathrm{a}$ (oak wood) including error bars indicating a measurement uncertainty of $\pm 1 \sigma$ are shown as a black line and black symbols, upper and lower bounds of the activation curve (see Sect. 2.4) are shown as gray lines, and the supersaturation where $50 \%$ of the particles are activated is indicated by a vertical dashed line. (b) The same $\mathrm{CCN} / \mathrm{CN}$ ratios plotted as a function of $\kappa$ corresponding to each $S$ measurement point (black symbols and line) with error bounds (gray symbols and lines). $\kappa_{\mathrm{CCN}}$, defined as the value of $\kappa$ where $50 \%$ of the particles are activated is indicated by a dotted line, and is substantially larger than $\kappa$ corresponding to $S_{\mathrm{c}}^{\mathrm{m}}\left(\kappa_{\mathrm{Sm}}\right.$; dashed line).

of the growth factor distribution should not be compared to the median of the CCN spectrum, because considerable errors will arise regardless of the interpolation method used.

\subsection{Error analysis}

Uncertainties in the H-TDMA measurements are dominated by uncertainties in RH. The system uncertainty in RH was determined by generating sodium chloride particles at 
regular intervals during the lab study and comparing their hygroscopic growth with theory, without using a shape factor correction. Rose et al. (2008) shows that, depending on the particle generation mechanism, $\mathrm{NaCl}$ particles generated by nebulization are in many cases compact spheres. Since the actual shape of the $\mathrm{NaCl}$ particles used in the calibration was not determined during the experiment, a shape factor of 1 was used. The calibration revealed that the system RH was stable within $\pm 2 \% \mathrm{RH}$. The relative uncertainty in hygroscopic growth factor (GF) for a sodium chloride particle at $85 \% \pm 2 \% \mathrm{RH}$ is roughly $\pm 3.5 \%$. The biomass burning particles studied here are much less hygroscopic than pure sodium chloride particles. Assuming that the activation curves are similar in shape, the relative uncertainty of the presented growth factor data is less than $2 \%$. For example, the estimated diameter growth factor of an idealized particle consisting of $30 \%$ levoglucosan and $70 \%$ insoluble material with a GF of 1.08 varies roughly by $\pm 1 \%$ over the $\mathrm{RH}$ range of $85 \pm 2 \%$. The diameter growth factors measured in this study typically varied between $\mathrm{GF}=1.04$ and 1.1 (at $\mathrm{RH}=85 \%$ ), so a typical variation of $\pm 1 \%$, with an upper limit of $\pm 2 \%$ seems reasonable for this study. A relative uncertainty of $2 \%$ in diameter growth factor translates to $40 \%$ in $\kappa_{\mathrm{G}}$ for $\mathrm{GF}=1.04$ and $20 \%$ in $\kappa_{\mathrm{G}}$ for $\mathrm{GF}=1.1$. However, since the variation with RH around a GF of 1.04 is less than $1 \%$, an overall relative uncertainty of roughly $20 \%$ is assumed for $\kappa_{\mathrm{G}}$ in this study. This error estimate an illustration of a typically expected uncertainty rather than an accurate quantitative error estimate. In reality, the uncertainty of GF depends only on the shape of the growth factor curve as a function of RH. This was not measured during the experiments and we therefore cannot say with certainty that the idealized particle is a good approximation of the biomass burning particles. While in principle a similar estimate could be done for each individual growth factor data point, this would not remove the underlying uncertainty regarding our chosen model particle, and give the impression of more quantitative knowledge than is actually available.

The method of estimating uncertainties in $\kappa_{\mathrm{CCN}}$ is illustrated in Fig. 2. The error bars (1 standard deviation) in Fig. 2a show the propagated uncertainty in $\mathrm{CCN} / \mathrm{CN}$ ratios and $S$ of a typical mean CCN spectrum (average over four individual CCN spectra taken at different times during the 1-h oak burning experiment). For some experiments, only three spectra were averaged, and in these cases the uncertainties are slightly larger. An upper bound to the spectrum is estimated using $\mathrm{CCN} / \mathrm{CN}+\delta \mathrm{CCN} / \mathrm{CN}$ ) and $S-\delta S$, a lower bound by using $\mathrm{CCN} / \mathrm{CN}-\delta \mathrm{CCN} / \mathrm{CN}$ ) and $S+\delta S$ (gray circles). $S-\delta S$ and $S+\delta S$ are converted to the respective upper and lower bounds of $\kappa$, which combined with the respective uncertainties in $\mathrm{CCN} / \mathrm{CN}$ result in the gray curves shown in Fig. $2 b$. The uncertainty of $\kappa_{\mathrm{CCN}}$ is estimated by finding $\mathrm{CCN} / \mathrm{CN}=0.5$ for each of these curves. For the oak experiment, this leads to uncertainty bounds for $\kappa_{\mathrm{CCN}}$ of $(0.09,0.16)$, or roughly $30 \%$, which represents a typi- cal uncertainty for the other biomass burning experiments as well. These error bounds only include the propagated error in $S$ and $\mathrm{CCN} / \mathrm{CN}$ and not the additional uncertainty caused by the low resolution of the spectra, which is impossible to assess accurately.

\section{Sensitivity studies}

Before analyzing the experimental data we need to evaluate the method of detecting SS and SA substances via comparison of $\kappa_{\mathrm{CCN}}$ and $\kappa_{\mathrm{G}}$ :

i. Can potential non-ideal behavior of the particle liquid phase lead to large differences in $\kappa_{\mathrm{G}}$ and $\kappa_{\mathrm{CCN}}$, without any presence of SA or SS substances?

ii. How sensitive is this method to the effects of SS and SA substances? i.e., how much surface tension suppression and what amount of slightly soluble material will lead to a significant difference in $\kappa_{\mathrm{G}}$ and $\kappa_{\mathrm{CCN}}$ ?

\subsection{Differences in $\kappa_{\mathrm{G}}$ and $\kappa_{\mathrm{CCN}}$ due to solution non-idealities}

In order to be detected, the differences in $\kappa_{\mathrm{CCN}}$ and $\kappa_{\mathrm{G}}$ caused by SA and SS compounds have to be substantially larger than the differences caused by potential solution non-idealities. Petters and Kreidenweis (2007) summarize $\kappa$ values derived from CCN and hygroscopic growth factor measurements for various inorganic substances. The differences are usually less than $15 \%$ and also include experimental uncertainties and in some cases effects of limited solubility and/or particle shape. Moreover, they are dependent on the RH at which the growth factors are measured. This makes it difficult to quantify the effect of solution non-ideality on the difference in $\kappa$ as one single number. However, since the data in Petters and Kreidenweis (2007) also include effects that could cause additional differences in $\kappa$, a $15 \%$ difference can be regarded as an upper limit for solution non-ideality effects. In the next sections we examine the effect of particle shape on $\kappa$ and then estimate the sensitivity of our method to SA and SS substances.

\subsection{The effect of particle shape on $\kappa_{\mathrm{CCN}}$ and $\kappa_{\mathrm{G}}$}

In this study, both the hygroscopic growth and the $\mathrm{CCN}$ activation are measured on particles pre-selected by a DMA according to their electrical mobility. These particles are assigned to a mobility equivalent diameter $\left(d_{\mathrm{m}}\right)$. The mobility diameter of non-spherical particles is larger than their volume equivalent diameter $\left(d_{\mathrm{ve}}\right)$. This has consequences for both $\mathrm{CCN}$ and diameter growth measurements and the calculation of $\kappa$.

The critical supersaturations derived from CCN measurements are an intrinsic property of the particles studied. However, the dry particle diameter is subsequently used in 
calculating $\kappa_{\mathrm{CCN}}$. A larger particle requires a smaller soluble volume fraction and therefore a lower $\kappa$ to be activated at the same $S_{\mathrm{c}}$ than a smaller particle. For non-spherical particles, $\kappa_{\mathrm{CCN}}$ calculated based on $d_{\mathrm{m}}$ is therefore smaller than $\kappa_{\mathrm{CCN}}$ based on $d_{\mathrm{ve}}$, which actually is the equivalent diameter more directly related to $\mathrm{CCN}$ activity.

The hygroscopic growth factor GF itself is defined as the ratio of the wet and dry diameter. If sufficient amounts of water condense on the particles, the wet particles are spherical and as a consequence their $d_{\mathrm{m}}$ and $d_{\mathrm{ve}}$ are equal. For the dry particles, however, $d_{\mathrm{m}}$ can be larger than $d_{\mathrm{ve}}$ depending on the particle shape. Since GF is operationally defined as the ratio of wet and dry mobility diameter, it may underpredict the actual volume of water condensed on the particle, and therefore underpredict $\kappa$.

The fact that $\kappa$ depends on the equivalent diameter used to describe the non-spherical particles does not necessarily limit its usefulness. The $\kappa$ values are mainly a simple way to parameterize the water uptake of aerosol particles and if they are used together with the diameter for which they are derived, they will give correct results for $S_{\mathrm{c}}$ and GF. However, for irregular particles of the same chemical composition, $\kappa_{\mathrm{G}}$ and $\kappa_{\mathrm{CCN}}$ can be different, even without surface tension effects or the influence of slightly soluble material. This could therefore lead to incorrect interpretations of our measurements. The biomass burning particles produced in the EFEU chamber appear as compact clusters of small spherules in the SEM (Dusek et al., 2005). They are not chain-like or highly fractal in nature and their shape factors have been determined to be $<1.2$ (Schneider et al., 2006), but could still exceed 1.

For the purpose of the following sensitivity studies we consider an idealized biomass burning particle consisting of $30 \%$ levoglucosan and $70 \%$ insoluble material that behaves as an ideal solution with a van't Hoff factor of 1 . This means we ignore the weak solution non-idealities (Mochida and Kawamura, 2004; Svenningsson et al., 2006) and the weak effect of levoglucosan on surface tension at high solute concentrations (e.g., Svenningsson et al., 2006). In this way we can study the desired effect without interference from nonideal solution effects.

First, we calculate the critical supersaturation and hygroscopic growth of the idealized biomass burning particle using the Köhler equation:

$\mathrm{RH}=a_{\mathrm{w}} \cdot \exp \left(\frac{4 \cdot \sigma \cdot M_{\mathrm{w}}}{\rho_{\mathrm{w}} \cdot R \cdot T \cdot d}\right)$

with

$a_{\mathrm{w}}=\frac{1}{1+i M_{\mathrm{w}} \eta}$

by numerically solving Eq. (6) for the interstitial diameter $d$ (and hence GF) at $\mathrm{RH}=0.85$, and by solving for the maximum to get $S_{\mathrm{c}}$.
Table 1. Volume equivalent diameters $\left(d_{\mathrm{ve}}\right)$, calculated hygroscopic growth factors (GF) at $85 \% \mathrm{RH}$, calculated critical supersaturation $\left(S_{\mathrm{C}}\right)$ and hygroscopicity parameters $\kappa_{\mathrm{G}}$ and $\kappa_{\mathrm{CCN}}$ of particles with a mobility diameter of $d_{\mathrm{m}}=100 \mathrm{~nm}$ and various shape factors $X=\{1.00,1.05,1.10\}$. The particles are assumed to consist of $30 \%$ levoglucosan and $70 \%$ insoluble material by volume. The 0.01 difference in $\kappa_{\mathrm{G}}$ and $\kappa_{\mathrm{CCN}}$ is most likely caused by slightly different Koehler approximations in modeling the idealized particle and the $\kappa$-Koehler theory.

\begin{tabular}{rrrrrr}
\hline$X$ & $d_{\mathrm{ve}}(\mathrm{nm})$ & $\mathrm{GF}$ & $\kappa_{\mathrm{G}}$ & $S_{\mathrm{c}}(\%)$ & $\kappa_{\mathrm{CCN}}$ \\
\hline 1 & 100 & 1.08 & 0.053 & 0.515 & 0.052 \\
1.05 & 95.8 & 1.04 & 0.023 & 0.548 & 0.046 \\
1.1 & 92.0 & 1.00 & 0 & 0.582 & 0.040 \\
\hline
\end{tabular}

Table 1 summarizes the influence of the shape factor $(X=$ $\left.d_{\mathrm{m}} / d_{\mathrm{ve}} \cdot C_{\mathrm{c}}\left(d_{\mathrm{ve}}\right) / C_{\mathrm{c}}\left(d_{\mathrm{m}}\right)\right)$, where $C_{\mathrm{c}}$ is the Cunningham slip correction factor) on $\kappa_{\mathrm{G}}$ and $\kappa_{\mathrm{CCN}}$, for a particle composed of $30 \%$ levoglucosan and $70 \%$ insoluble material, assuming a mobility diameter of $d_{\mathrm{m}}=100 \mathrm{~nm}$ is selected by the DMA. The second column in Table 1 shows the decrease in $d_{\mathrm{ve}}$ with increasing shape factor. The equilibrium wet diameter $\left(d_{\mathrm{wet}}\right)$ is calculated using Eqs. (6-7) and the respective $d_{\mathrm{ve}}$. To approximate the measured growth factor we then use the calculated $d_{\text {wet }}$ and a $d_{\mathrm{m}}$ of $100 \mathrm{~nm}$, in the same way as the data would be evaluated if the shape factor were not known. The measured hygroscopic growth factor GF, defined as $d_{\text {wet }} / d_{\mathrm{m}}$, decreases strongly with increasing $X$, i.e., the derived $\kappa_{\mathrm{G}}$ will be too small and increasingly so with increasing shape factor. Also, the critical supersaturations were determined using Eqs. (6) and (7). Since the critical supersaturation depends inversely on the amount of soluble material in the particle, it increases with decreasing $d_{\mathrm{ve}}$. However, the resulting reduction in $\kappa_{\mathrm{CCN}}$ is much more moderate than the reduction in $\kappa_{\mathrm{G}}$. We can deduce from this example that slight variations in shape factor cause a larger variation in $\kappa_{\mathrm{G}}$ than $\kappa_{\mathrm{CCN}}$.

\subsection{Sensitivity of $\kappa$ to surface tension depression}

The sensitivity of $\kappa_{\mathrm{CCN}}$ to SA compounds is assessed by theoretically estimating $\mathrm{Sc}$ values that would be measured by a CCN counter, if the surface tension at activation were reduced compared to that of water. From this $S_{\mathrm{c}}, \kappa_{\mathrm{CCN}}$ values are derived, assuming the surface tension of water, as would be done in a standard $\kappa$ calculation. For these calculations, we artificially reduce the surface tension of the idealized biomass burning particle to $90 \%$ and $80 \%$ of the value of pure water. This reduces the critical supersaturation of the particle as shown in Table 2, and as a consequence increases $\kappa_{\mathrm{CCN}}$. The initial $\kappa_{\mathrm{CCN}}$ value of the model aerosol at the surface tension of water is 0.052 and increases to approximately 0.1 by reducing the surface tension to $80 \%$ of its original value. This shows that reducing the surface tension by $20 \%$, 
Table 2. Calculated critical supersaturations $S_{\mathrm{c}}$ and effective hygroscopicity parameters $\kappa_{\mathrm{CCN}}$ for an idealized biomass burning particle consisting of $30 \%$ levoglucosan and $70 \%$ insoluble material at temperature $T=293 \mathrm{~K}$, assuming that the surface tension at the point of activation is 0.9 and 0.8 time that of water. $\kappa_{\mathrm{CCN}}$ for the original particle (surface tension of water) is 0.052 , see also Table 1 . $\kappa_{\mathrm{G}}$ remains at 0.053 .

\begin{tabular}{rccccc}
\hline$d_{\mathrm{p}}$ & $\begin{array}{c}S_{\mathrm{c}}(\%) \\
0.9 \sigma\end{array}$ & $\begin{array}{c}S_{\mathrm{c}}(\%) \\
0.8 \sigma\end{array}$ & $\begin{array}{c}\kappa_{\mathrm{CCN}} \\
0.9 \sigma\end{array}$ & $\begin{array}{c}\kappa_{\mathrm{CCN}} \\
0.8 \sigma\end{array}$ & $\kappa_{\mathrm{G}}$ \\
\hline 50 & 1.21 & 1.02 & 0.074 & 0.11 & 0.053 \\
100 & 0.44 & 0.37 & 0.073 & 0.10 & 0.053 \\
150 & 0.24 & 0.20 & 0.072 & 0.10 & 0.053 \\
\hline
\end{tabular}

results in a doubling of $\kappa_{\mathrm{CCN}}$. From the last column of Table 2 it can be seen that the increase in the value of $\kappa_{\mathrm{CCN}}$ is almost independent of particle diameter.

$\kappa_{\mathrm{G}}$ is influenced only slightly by a change in surface tension at $85 \% \mathrm{RH}$ and remains around 0.053 since the Kelvin effect is small for particles larger than $50 \mathrm{~nm}$ as considered here (see Eq. (6), exponential term), which was also found by Wex et al. (2008b). We can therefore conclude that a surface tension reduction of more than $10 \%$ results in a larger difference between $\kappa_{\mathrm{CCN}}$ and $\kappa_{\mathrm{G}}$ than would be expected from non-ideal solution effects. Therefore we are able to resolve moderate changes in surface tension (larger than $10 \%$ ) by comparing $\kappa_{\mathrm{CCN}}$ and $\kappa_{\mathrm{G}}$.

\subsection{Sensitivity of $\kappa$ to slightly soluble substances}

Slightly soluble substances alter the expected critical supersaturation most drastically if they are virtually undissolved at subsaturated conditions, but fully dissolved at supersaturated conditions near $S_{\mathrm{c}}$. We choose succinic acid as an example of a SS substance, due to its moderate solubility of $88 \mathrm{~g} \mathrm{l}^{-1}$ at $25^{\circ} \mathrm{C}$ (Saxena and Hildemann, 1996). The moderate reduction in surface tension due to succinic acid at high solution concentrations was ignored for the following sensitivity study to focus solely on the solubility effect.

We calculated critical supersaturations and hygroscopic growth factors for a particle consisting of levoglucosan and succinic acid in varying proportions, again treating them as ideal solutions. We use the form of the Köhler equation as written in Eq. (6), but with

$a_{\mathrm{w}}=\frac{1}{1+\frac{6 M_{\mathrm{w}} m_{1}}{\pi M_{\mathrm{l}} \rho_{\mathrm{w}}\left(d^{3}-d_{\mathrm{dry}}^{3}\right)}+\frac{M_{\mathrm{w}} \mathrm{sol}}{M_{\mathrm{ss}} \rho_{\mathrm{w}}}}$

when succinic acid is not completely dissolved and

$a_{\mathrm{w}}=\frac{1}{1+\frac{6 M_{\mathrm{w}}}{\left.\pi \rho_{\mathrm{w}} d^{3}-d_{\mathrm{dry}}^{3}\right)}\left(\frac{m_{1}}{M_{\mathrm{l}}}+\frac{m_{\mathrm{ss}}}{M_{\mathrm{ss}}}\right)}$
Table 3. Critical supersaturations $\left(S_{\mathrm{c}}\right)$ and hygroscopic diameter growth factors (GF) (at $85 \% \mathrm{RH}$ ) for a particle consisting of levoglucosan and succinic acid in varying proportions. Calculations were made at temperature $T=293 \mathrm{~K}$.

\begin{tabular}{|c|c|c|c|c|c|c|}
\hline \multirow[b]{2}{*}{$d_{\mathrm{p}}(\mathrm{nm})$} & \multicolumn{2}{|c|}{$0 \%$ succinic } & \multicolumn{2}{|c|}{$50 \%$ succinic } & \multicolumn{2}{|c|}{$90 \%$ succinic } \\
\hline & $S_{\mathrm{c}}(\%)$ & GF & $S_{\mathrm{c}}(\%)$ & GF & $S_{\mathrm{c}}(\%)$ & GF \\
\hline 50 & 0. & 1.2 & 0 . & 1.1 & 0.71 & 1.03 \\
\hline 100 & 0.29 & 1.24 & 0.27 & 1.13 & 0.25 & 1.03 \\
\hline 150 & 0.16 & 1.24 & 0.15 & 1.14 & 0.14 & 1.03 \\
\hline
\end{tabular}

Table 4. Hygroscopicity parameters derived from $\mathrm{CCN}$ properties $\left(\kappa_{\mathrm{CCN}}\right)$ and hygroscopic growth factors $\left(\kappa_{\mathrm{G}}\right)$ for a particle consisting of levoglucosan and succinic acid in varying proportions. The respective values of $S_{\mathrm{c}}$ and GF used in the calculations can be found in Table 3.

\begin{tabular}{rcccccc}
\hline \multicolumn{3}{c}{$0 \%$ succinic } & \multicolumn{2}{c}{$50 \%$ succinic } & \multicolumn{2}{c}{$90 \%$ succinic } \\
$d_{\mathrm{p}}(\mathrm{nm})$ & $\kappa_{\mathrm{CCN}}$ & $\kappa_{\mathrm{G}}$ & $\kappa_{\mathrm{CCN}}$ & $\kappa_{\mathrm{G}}$ & $\kappa_{\mathrm{CCN}}$ & $\kappa_{\mathrm{G}}$ \\
\hline 50 & 0.17 & 0.18 & 0.20 & 0.091 & 0.23 & 0.018 \\
100 & 0.17 & 0.17 & 0.20 & 0.094 & 0.23 & 0.017 \\
150 & 0.17 & 0.17 & 0.20 & 0.090 & 0.23 & 0.019 \\
\hline
\end{tabular}

when succinic acid is completely dissolved. The term sol is the solubility of succinic acid. The subscript " $w$ " denotes water, "l" denotes levoglucosan and "ss" the slightly soluble substance (in this case succinic acid). Van't Hoff factors of 1 are assumed for both levoglucosan and succinic acid.

$S_{\mathrm{c}}$ and GF of the model particles are summarized in Table 3 . The critical supersaturations are not strongly affected by the increasing mass fractions of succinic acid as a consequence of the similar density and molecular weight of succinic acid and levoglucosan and the fact that succinic acid is nearly fully dissolved at the point of activation. The hygroscopic growth factors, however, decrease drastically (from about 1.24 to 1.03 ) when levoglucosan is replaced by the nearly undissolved succinic acid at $\mathrm{RH}=85 \%$.

Table 4 shows $\kappa$ calculated from $S_{\mathrm{c}}$ and GF in Table 3. For pure levoglucosan particles, $\kappa_{\mathrm{G}}$ and $\kappa_{\mathrm{CCN}}$ are similar, but with increasing succinic acid fractions, $\kappa_{\mathrm{G}}$ is reduced to roughly $1 / 2$ and $1 / 5$ of $\kappa_{\mathrm{CCN}}$. These results can also be interpreted in the light of the $\kappa$ mixing rule, which states that $\kappa$ of a mixed particle can be estimated as average $\kappa$ of its individual components weighted by their volume fraction $(\varepsilon)$. At a RH of $85 \%$, where succinic acid is not dissolved $\kappa_{\text {succ }}=0$. Therefore $\kappa_{\mathrm{G}}$ can be calculated as $\kappa_{\mathrm{G}}=\kappa_{\mathrm{lev}} \cdot \varepsilon_{\mathrm{lev}}$, and $\kappa_{\mathrm{CCN}}=\kappa_{\mathrm{lev}} \cdot \varepsilon_{\mathrm{lev}}+\kappa_{\mathrm{succ}} \cdot \varepsilon_{\mathrm{succ}}$. It is clear that the magnitude of the difference between $\kappa_{\mathrm{G}}$ and $\kappa_{\mathrm{CCN}}$ depends both on the amount and $\kappa$ of the slightly soluble material. Through the strong effect on $\kappa_{\mathrm{G}}$, however, we conclude that significant fractions of slightly soluble material can cause a large 
difference in $\kappa_{\mathrm{G}}$ and $\kappa_{\mathrm{CCN}}$. This difference can easily exceed the difference caused by non-ideal solution effects and can be detected with our model, if there is no interference from surface active compounds and/or shape effects.

In summary, the presence of surfactants, the presence of slightly soluble substances, and non-spherical particle shape, all can cause $\kappa_{\mathrm{CCN}}$ to be larger than $\kappa_{\mathrm{G}}$. Therefore with measurements at one single particle diameter it is not possible to distinguish these three factors. However, only the surface tension effect on $\kappa_{\mathrm{CCN}}$ shows a dependence on particle size, with increasing differences between $\kappa_{\mathrm{CCN}}$ and $\kappa_{\mathrm{G}}$ expected at smaller diameters. The dependence of $\kappa_{\mathrm{G}}$ and $\kappa_{\mathrm{CCN}}$ on particle size can therefore give a possible distinction between the effects of surface tension depression or those of the other two factors.

\section{Results}

We analyzed nine of the wood burning experiments, comprising all experiments for which both hygroscopic growth factors and CCN spectra were available. These included two experiments burning hardwood fuels (oak and musasa), three experiments burning softwood fuels (pine and spruce) and four experiments burning softwood fuels along with fresh or dry branches and needles. Chemical analyses of impactor samples (Iinuma et al., 2007) were available for six of those experiments.

Figure 3 and Table 5 show grand averages of $\kappa_{\mathrm{G}}$ and $\kappa_{\mathrm{CCN}}$. $\kappa$ of freshly emitted wood burning aerosol is generally small. The $\kappa$ values from our experiment compare well to the range of $\kappa$ values (0.05-0.2) obtained by Petters et al. (2009) for similar fuel types (i.e., wood or branches with needles or leaves). Petters et al. (2009) found that grasses and other materials, such as sugar cane or rice straw, were generally more hygroscopic.

Although individual values of $\kappa$ have large uncertainties, the averages over many experiments agree well for 100 and $150 \mathrm{~nm}$. However, for $50 \mathrm{~nm}$ particles, $\kappa_{\mathrm{CCN}}$ and $\kappa_{\mathrm{G}}$ differ significantly at the $95 \%$ confidence level (t-test, paired two sample for means). Moreover, $\kappa_{\mathrm{CCN}}$ and $\kappa_{\mathrm{G}}$ show opposing trends with particle size. The values of $\kappa_{\mathrm{CCN}}$ increase linearly with decreasing particle diameter, whereas $\kappa_{\mathrm{G}}$ is similar for 100 and $150 \mathrm{~nm}$ particles but decreases somewhat for $50 \mathrm{~nm}$ particles. Petters et al. (2009) also observed good agreement between $\kappa$ derived from hygroscopic growth factors and CCN spectra around the $100 \mathrm{~nm}$ size range. However, they also note an increase in hygroscopic growth factors towards smaller particle sizes, which we did not observe in this study.

The increase in $\kappa_{\mathrm{CCN}}$ with decreasing size would be consistent with the possibility that smaller particles contain a $50 \%$ higher fraction of soluble material than larger particles. This could be expected, if soluble material condenses on preexisting soot cores during the cooling of the vaporized ma-

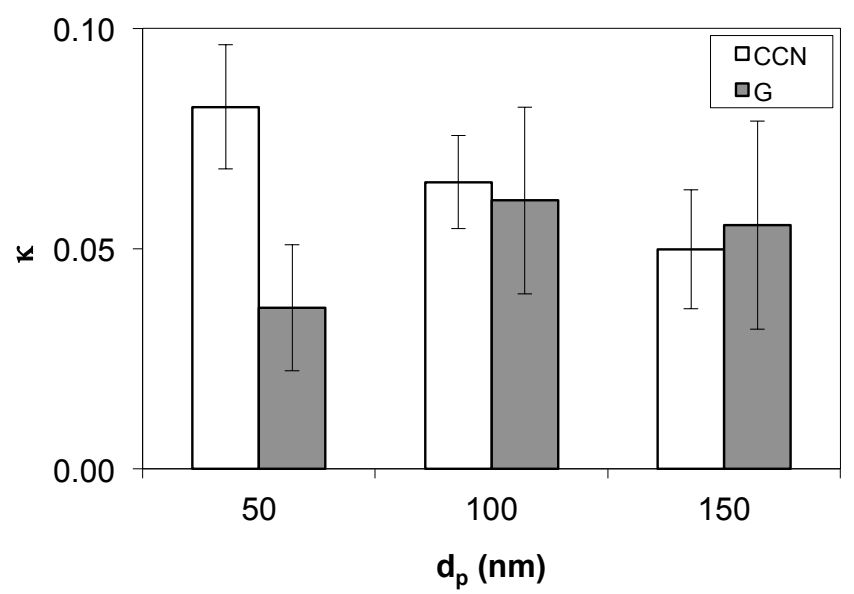

Fig. 3. Grand averages (of all nine experiments) of hygroscopicity parameters derived from hygroscopic growth factors $\left(\kappa_{\mathrm{G}}\right)$ shown as gray bars and from $\mathrm{CCN}$ spectra $\left(\kappa_{\mathrm{CCN}}\right)$ shown as white bars. The error bars correspond to 1 standard deviation of the data.

Table 5. Average hygroscopicity parameters $(\kappa)$ plus standard deviations for freshly emitted wood burning particles. The values represent averages over all nine biomass burning experiments.

\begin{tabular}{rcc}
\hline$d_{\mathrm{p}}(\mathrm{nm})$ & $\kappa_{\mathrm{G}}$ & $\kappa_{\mathrm{CCN}}$ \\
\hline 50 & $0.037 \pm 0.014$ & $0.082 \pm 0.014$ \\
100 & $0.061 \pm 0.021$ & $0.065 \pm 0.011$ \\
150 & $0.055 \pm 0.024$ & $0.050 \pm 0.014$ \\
\hline
\end{tabular}

terial. However, in this case $\kappa_{\mathrm{G}}$ should increase as well, and therefore the decrease in $\kappa_{\mathrm{G}}$ at $50 \mathrm{~nm}$ renders this hypothesis relatively unlikely. A $50 \%$ increase in the soluble fraction that does not increase $\kappa_{\mathrm{G}}$ could only be explained if most of this added material was only slightly soluble. However there is no likely reason why slightly soluble material should be enriched in $50 \mathrm{~nm}$ particles to such an extent.

It is also difficult to explain the difference between $\kappa_{\mathrm{G}}$ and $\kappa_{\mathrm{CCN}}$ at small particle sizes by particle shape effects. In principle the small particles could be more irregular in shape, for example if they contained less soluble material than larger particles. However, then $\kappa_{\mathrm{CCN}}$ should also be lower for $50 \mathrm{~nm}$ particles than for larger particles, although the effect for $\kappa_{\mathrm{CCN}}$ should be less than for $\kappa_{\mathrm{G}}$. In this case, either surface tension effects or an increase in soluble volume fractions larger than $50 \%$ would have to be invoked to explain the observed increase of $\kappa_{\mathrm{CCN}}$ with deceasing particles size. However, more organic material would almost certainly lead to more spherical particles.

Therefore, the most likely explanation for the observed increase in $\kappa_{\mathrm{CCN}}$ without a concurrent increase in $\kappa_{\mathrm{G}}$ is the presence of surfactant organics. At the point of critical supersaturation, the droplets that form by condensation on small 
particles are more concentrated than droplets that form on larger particles. The surface tension of surfactant solutions tends to decrease with solution concentration (e.g., Facchini et al., 2000; Svenningsson et al., 2006). Therefore, it is possible that surface active material is relatively ineffective at large particle sizes, but begins to significantly decrease the critical supersaturation for small particles.

Figure 4 presents scatter plots of $\kappa_{\mathrm{CCN}}$ versus $\kappa_{\mathrm{G}}$ for each particle diameter. Each data point represents an individual burning experiment of approximately one hour. Hardwood fuels (musasa, oak) are indicated as black squares, softwood fuels (spruce, pine) as white circles, and softwood fuels including needles and branches as gray triangles. The error bars show the respective experimental uncertainties in $\kappa$ (see Sect. 3.4). At $50 \mathrm{~nm}$ the difference between $\kappa_{\mathrm{G}}$ and $\kappa_{\mathrm{CCN}}$ is clearly outside the range that could be explained by experimental uncertainties.

Individual values of $\kappa_{\mathrm{CCN}}$ and $\kappa_{\mathrm{G}}$ are not strongly correlated. This is partially due to the limited range of $\kappa$ values and to the large experimental uncertainty, which results in significant scatter of the data points. However, the experimental uncertainties cannot explain all the variability and lack of correlation in the data set. Another part of the variability is probably due to the fact that $\mathrm{CCN}$ and growth factor measurements did not take place at exactly the same times during each experiment. Furthermore, there is a systematic difference in variability between $\kappa_{\mathrm{CCN}}$ and $\kappa_{\mathrm{G}}$. Despite comparable experimental uncertainties, the $\kappa_{\mathrm{G}}$ data have roughly twice the relative standard deviation of the $\kappa_{\mathrm{CCN}}$ data. Moreover, the correlation between $\kappa_{\mathrm{G}}$ of $50 \mathrm{~nm}$ and $\kappa_{\mathrm{G}}$ of $100 \mathrm{~nm}$ particles is poor $\left(R^{2}=0.29\right)$, whereas $\kappa_{\mathrm{CCN}}$ of 50 and $\kappa_{\mathrm{CCN}}$ of $100 \mathrm{~nm}$ particles are tightly correlated $\left(R^{2}=0.90\right)$. This means that in fuels where $50 \mathrm{~nm}$ particles were easily activated, $100 \mathrm{~nm}$ particles were easily activated as well, whereas at subsaturated conditions there does not seem to exist a clear relationship between the hygroscopicity of the 50 and $100 \mathrm{~nm}$ particles.

The larger scatter in the growth factor data could be caused by a potential non-spherical shape of the biomass burning particles. However, this is in contradiction to the fact that the mean $\kappa_{\mathrm{G}}$ and $\kappa_{\mathrm{CCN}}$ are comparable, since the shape effect would reduce the measured hygroscopic growth factor and would lead to an underestimate of $\kappa_{\mathrm{G}}$. Therefore particle shape is not a likely explanation. It is also possible that our simple estimate of uncertainty in Sect. 3.3 underestimates the uncertainty of growth factor measurements.

Figure 5 shows volume fractions of soluble material estimated from the chemical composition of impactor samples (Iinuma et al., 2007). For this comparison, we used the first impactor stage, which had aerodynamic cut-off diameters of 50 and $150 \mathrm{~nm}$. This corresponds to 36 and $125 \mathrm{~nm}$ volume equivalent diameters, assuming a density of $1600 \mathrm{~kg} \mathrm{~m}^{-3}$ for the biomass burning particles or to 44 and $140 \mathrm{~nm}$ using a density of $1200 \mathrm{~kg} \mathrm{~m}^{-3}$. The black bars represent volume fractions of inorganic ions and the gray bars represent (a) $50 \mathrm{~nm}$

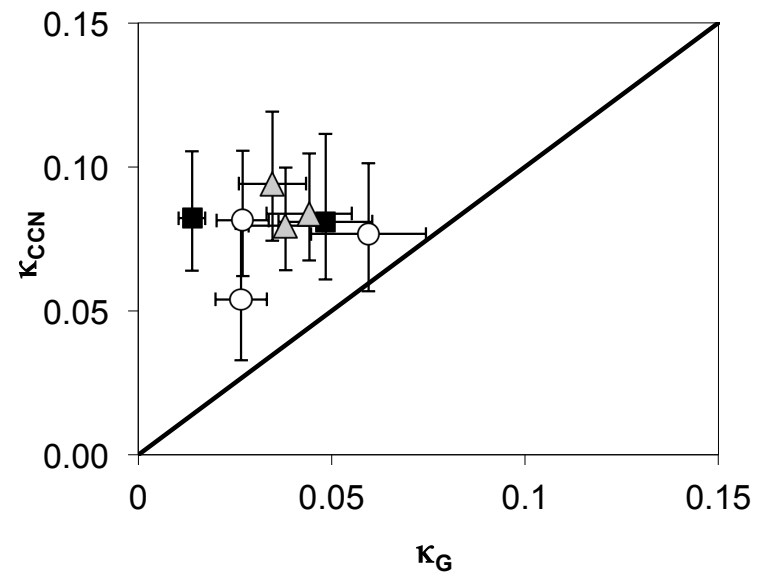

(b) $100 \mathrm{~nm}$

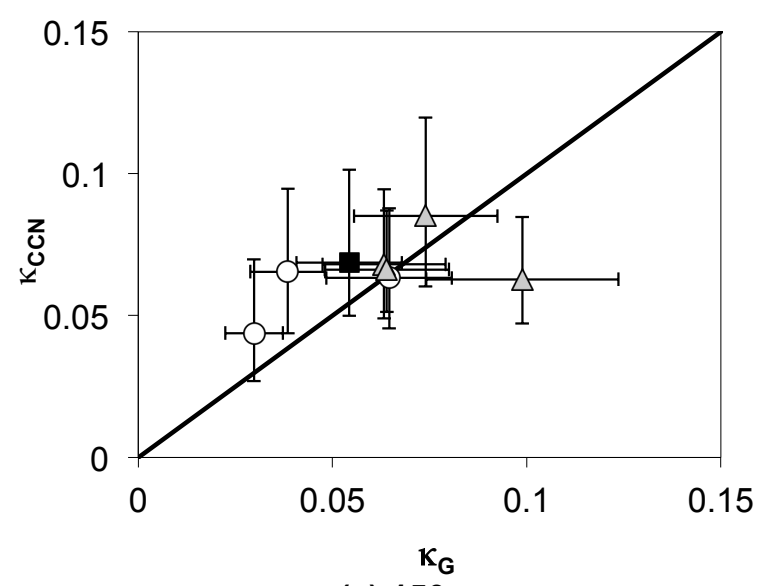

(c) $150 \mathrm{~nm}$

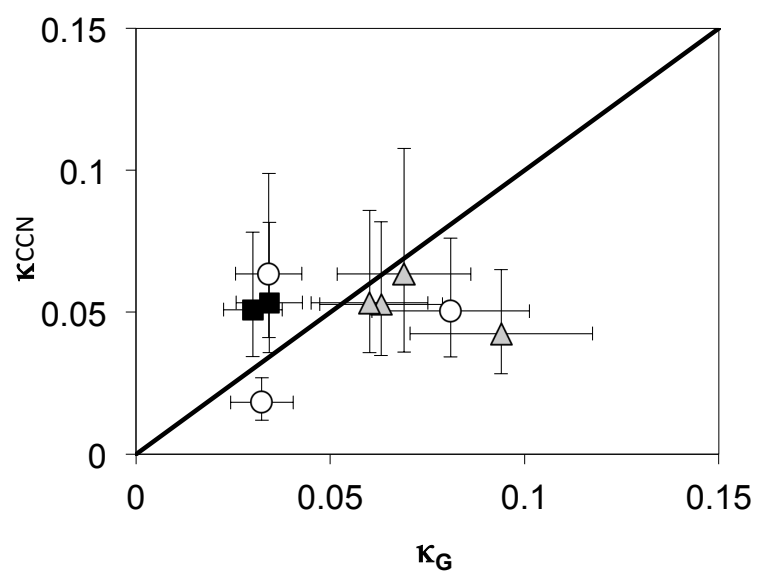

Fig. 4. Correlation between $\kappa_{\mathrm{CCN}}$ and $\kappa_{\mathrm{G}}$ at different particle diameters. Each data point represents an individual biomass burning event of approximately $1 \mathrm{~h}$. Hardwood fuels (musasa, oak) are indicated as black squares, softwood fuels (spruce, pine) as white circles, and softwood fuels including needles and branches as gray triangles. 


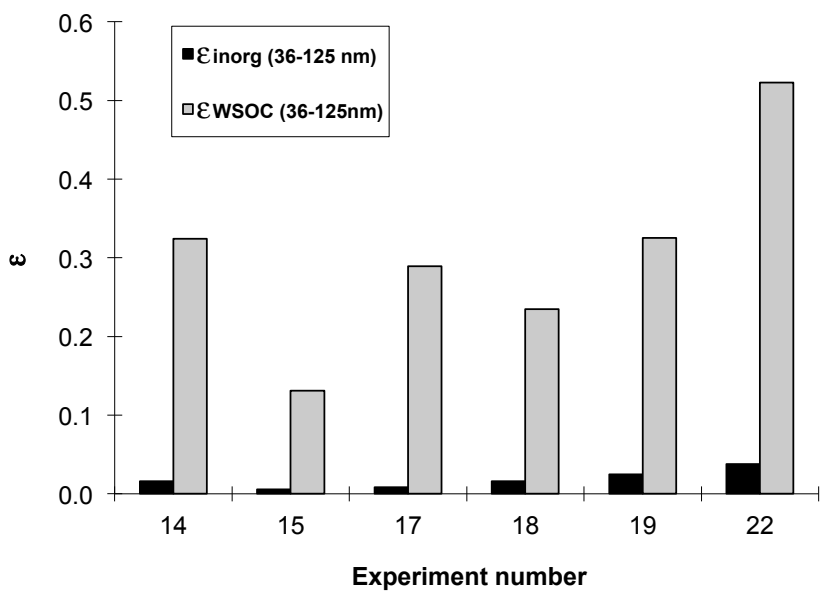

Fig. 5. Volume fraction of inorganic ions (black bars) and water soluble organic carbon (WSOC; gray bars) estimated from impactor samples. Fuel types are for the individual experiments are: Hardwood $(14,19)$; Softwood $(15,17)$; Softwood and green needles $(18$, 22).

volume fractions of water soluble organic carbon, $\varepsilon$ Wsoc. These volume fractions are rough estimates using densities of $1700 \mathrm{~kg} \mathrm{~m}^{-3}$ for the inorganic fraction, $2000 \mathrm{~kg} \mathrm{~m}^{-3}$ for elemental carbon, $1400 \mathrm{~kg} \mathrm{~m}^{-3}$ for the organic fraction, and $1500 \mathrm{~kg} \mathrm{~m}^{-3}$ for the unresolved material. The water soluble fraction of the first impactor stage is dominated by organic material, and volume fractions of inorganic ions are low for all wood burning experiments.

Based on this comparison, it is possible to give a rough estimate of the effectiveness of the WSOC fraction with respect to water uptake. The hygroscopicity parameter of the biomass burning particle can be calculated as the volume weighted average of $\kappa$ of the individual components $\left(\kappa=\kappa_{\text {inorg }} \cdot \varepsilon_{\text {inorg }}+\kappa_{\mathrm{WSOC}} \cdot \varepsilon_{\mathrm{WSOC}}\right)$. For each experiment where impactor data are available, we calculate $\kappa$ of the biomass burning particles as a volume weighted average for both $\kappa_{\mathrm{CCN}}$ and $\kappa_{\mathrm{G}}$ values at 50 and $100 \mathrm{~nm}$, which lie within the range of impactor stage 1 . For each of the available experiments we estimate $\kappa$ WSOC as follows: We assume that $\kappa_{\text {inorg }}$ is roughly 0.6 , which is an average of growth-factor-derived and $\mathrm{CCN}$-derived $\kappa$ of ammonium sulfate and $\mathrm{CCN}$-derived $\kappa$ of ammonium nitrate from Petters and Kreidenweis (2006). Using $\varepsilon_{\text {inorg }}$ and $\varepsilon_{\text {WSOC }}$ from Fig. 5 we arrive at $\kappa_{\text {WSOC }}$ values ranging from 0.07 to 0.43 with an average of $0.2 \pm 0.1$. This means that the water-soluble organic material can be represented by a $\kappa$ value which is higher than the $\kappa$ value of $\sim 0.1$ suggested for fresh secondary organic aerosol (e.g., Dusek et al., 2010; Petters and Kreidenweis, 2007), but close to the value of levoglucosan (Petters and Kreidenweis, 2007). The effective hygroscopicity of a typical wood burning particle can therefore be represented by a linear mixture of an inorganic component with $\kappa \cong 0.6$, a WSOC component with $\kappa \cong 0.2$, and an insoluble component with $\kappa=0$.
Table 6. Critical supersaturation $\left(S_{\mathrm{c}}\right)$, surface tension at activation $(\sigma)$ and hygroscopicity parameter $\left(\kappa_{\mathrm{CCN}}\right)$ for a particle consisting of $30 \%$ levoglucosan, $5 \%$ fulvic acid and $65 \%$ insoluble material at various particle diameters $\left(d_{\mathrm{p}}\right)$.

\begin{tabular}{rccc}
\hline$d_{\mathrm{p}}(\mathrm{nm})$ & $S_{\mathrm{c}}(\%)$ & $\sigma\left(\mathrm{mN} \mathrm{m}^{-1}\right)$ & $\kappa_{\mathrm{CCN}}$ \\
\hline 50 & 1.09 & 63.3 & 0.093 \\
100 & 0.45 & 66.8 & 0.069 \\
150 & 0.26 & 69.1 & 0.062 \\
\hline
\end{tabular}

\section{Discussion}

\subsection{The role of surfactants}

The presence of SA substances is a plausible explanation for the increase of $\kappa_{\mathrm{CCN}}$ with decreasing particle size and for the difference between $\kappa_{\mathrm{CCN}}$ and $\kappa_{\mathrm{G}}$ at $50 \mathrm{~nm}$. Iinuma et al. (2007) show that the pyrogenic particles studied during the EFEU experiment contained a significant amount of macromolecules. While the nature of these macromolecules is not entirely certain, it has been shown previously (e.g., Facchini et al., 2000; Dinar et al., 2006; Fors et al., 2010), that macromolecular substances such as humic like substances (HULIS) can have a strong effect on droplet surface tension.

It is known in principle that SA substances cause an apparent increase in $\kappa_{\mathrm{CCN}}$ with decreasing particle size, since an equal fraction of surfactant is more concentrated in solution droplets forming on small particles. However, it still needs to be explored whether a realistic SA substance can account for the observed increase in $S_{\mathrm{c}}$ solely due to the concentration effect. Therefore, we conducted an estimate, considering an idealized biomass burning particle with a composition of $30 \%$ levoglucosan, $5 \%$ fulvic acid and $65 \%$ insoluble material. The dependence of droplet surface tension on fulvic acid concentration is parameterized according to Svenningsson et al. (2006). Table 6 shows that even though particles of 50, 100 , and $150 \mathrm{~nm}$ contain the same fraction of surfactant, the surface tension of the droplet at $S_{\mathrm{c}}$ decreases with decreasing dry particle diameter. The resulting increase of $\kappa_{\mathrm{CCN}}$ of the model particle is comparable to that observed with the actual biomass burning particles (Fig. 3).

This sensitivity study shows that a small amount of surfactant similar to fulvic acid could cause the observed increase in $\kappa_{\mathrm{CCN}}$ with decreasing particle diameter and the resulting difference in $\kappa_{\mathrm{CCN}}$ and $\kappa_{\mathrm{G}}$. This strengthens the evidence that surfactants modify the $\mathrm{CCN}$ activation of fresh biomass burning particles at small particle sizes. 


\subsection{Water interaction in relation to chemical speciation}

Figure 5 strongly suggests that the water uptake of fresh biomass burning particles from wood burning is mainly governed by organic material, with only a small contribution from inorganic compounds. The organic fraction of fresh biomass burning particles is strongly soluble and its hygroscopicity can be represented by a $\kappa$ of roughly 0.2 . These results fit well with observations that levoglucosan is by far the dominant individual organic component of fresh biomass burning aerosol (Iinuma et al., 2007). Levoglucosan has a similar molecular weight and density as ammonium sulfate, but a smaller van't Hoff factor, around 1 (Mochida and Kawamura, 2004), instead of roughly 2.3-3. Assuming the WSOC fraction to consist of pure levoglucosan predicts water uptake that slightly overestimates the measured water uptake. This could be the presence of macromolecules as detected by Iinuma et al. (2007) that increase the mean molecular mass of the water soluble fraction. However, considering the high uncertainties associated with estimating WSOC fractions from impactor measurements, approximating the WSOC fraction with levoglucosan leads to a reasonable estimate of $S_{\mathrm{c}}$.

\subsection{Atmospheric relevance}

In this study, we find indications for an enhancement of $\mathrm{CCN}$ activation due to a possible decrease in droplet surface tension as proposed by Facchini et al. (1999). For fresh biomass burning particles, this effect is important for particles of around $50 \mathrm{~nm}$ or smaller, for which the solution droplets are sufficiently concentrated at their critical supersaturation. However, the $50 \mathrm{~nm}$ particles typically require supersaturations of $1 \%$ or above for activation, and are therefore not very important $\mathrm{CCN}$ under atmospheric conditions and ambient particle size distributions, where usually a considerable number of larger particles is also present. For lower supersaturations, more typical of ambient clouds, the surface tension does not strongly affect the $\mathrm{CCN}$ properties. The critical supersaturations of fresh biomass burning particles can then be predicted reasonably well from the known water uptake at subsaturated conditions using the $\kappa$ parameterization.

As particles age in the biomass burning plumes, they acquire more water soluble material through photochemical processes. Decesari et al. (2006) found that in ambient aerosol during the Amazon biomass burning season, levoglucosan was only one constituent among many, such as mono/dicarboxylic acids, sugars, sugar alcohols, polyhydroxylated species and others. Humic-like substances can become further enriched due to polymerization processes (Kalberer et al., 2004). For these aged biomass burning particles, slightly soluble material might be present and surface tension effects might be stronger, so that the simple $\kappa$ model might not be appropriate any more. This might be the reason why Rissler et al. (2004) needed a more complex model to successfully predict $\mathrm{CCN}$ concentrations from size distributions and hygroscopic diameter growth factors.

\section{Conclusions}

We derived hygroscopicity parameters of freshly emitted biomass burning particles from size-resolved hygroscopic diameter growth factors $\left(\kappa_{\mathrm{G}}\right)$ and $\mathrm{CCN}$ spectra $\left(\kappa_{\mathrm{CCN}}\right)$. The $\kappa$ values of freshly emitted biomass burning particles are small, ranging between 0.02 and 0.15 . This means that the water uptake of the biomass particles is equivalent to particles consisting of 5-20\% ammonium sulfate and otherwise insoluble material. The fraction of inorganic ions in impactor samples of the biomass burning particles is much smaller than $5-20 \%$, indicating that the water uptake is mainly governed by organic material.

One main emphasis of this study was to compare $\kappa_{\mathrm{G}}$ and $\kappa_{\mathrm{CCN}}$ to gain information about the possible influence of surface active or slightly soluble substances on CCN activation. Previous studies show that unless surface active or slightly soluble substances are present in the particles, the soluble volume fractions, $\kappa_{\mathrm{G}}$ and $\kappa_{\mathrm{CCN}}$, should be comparable within $15 \%$. We found a significant difference in $\kappa_{\mathrm{G}}$ and $\kappa_{\mathrm{CCN}}$ only for small particles $(50 \mathrm{~nm})$, but not for particles 100 and $150 \mathrm{~nm}$ in diameter. This behavior is consistent with the presence of a surfactant that facilitates droplet activation leading to a larger inferred $\kappa_{\mathrm{CCN}}$ than $\kappa_{\mathrm{G}}$. Even if the volume fraction of the surfactant is constant for all dry particles sizes, it will be more concentrated in deliquescent droplets that form on small particles and more dilute in droplets forming on larger particles. This explains that the effect is only visible at small particle sizes. The observed increase in $\kappa_{\mathrm{CCN}}$ with decreasing particle diameter could be reproduced with an idealized biomass burning particle consisting of $30 \%$ levoglucosan, $65 \%$ insoluble material, and $5 \%$ fulvic acid, indicating that only a small amount of surfactant is necessary for the observed effects.

Acknowledgements. This work was funded by the Max Planck Society and by the Federal Ministry of Education and Research (BMWF, Germany) under the Atmospheric Research Program 2000 (AFO2000), grant nr.: 07ATF46 (EFEU). We thank M. Welling and R. S. Parmar for support during the burning experiments and two anonymous reviewers for valuable comments.

The service charges for this open access publication have been covered by the Max Planck Society.

Edited by: M. Ammann 


\section{References}

Andreae, M. O. and Gelencsér, A.: Black carbon or brown carbon? The nature of light-absorbing carbonaceous aerosols, Atmos. Chem. Phys., 6, 3131-3148, doi:10.5194/acp-6-3131-2006, 2006.

Andreae, M. O. and Rosenfeld, D.: Aerosol-cloud-precipitation interactions. Part 1. The nature and sources of cloud-active aerosols, Earth Sci. Rev., 89, 13-41, 2008.

Berner, A. and Lürzer C.: Mass size distributions of traffic aerosols at Vienna, J. Phys. Chem., 84, 2079-2083, 1987.

Brechtel, F. J. and Kreidenweis, S. M.: Predicting particle critical supersaturation from hygroscopic growth measurements in the humidified TDMA. part I: Theory and sensitivity studies, J. Atmos. Sci., 57, 1854-1871, 2000a.

Brechtel, F. J. and Kreidenweis, S. M.: Predicting particle critical supersaturation from hygroscopic growth measurements in the humidified TDMA. Part II: Laboratory and ambient studies, J. Atmos. Sci., 57, 1872-1887, 2000b.

Covert, D. S., Gras, J. L., Wiedensohler, A., and Stratmann, F.: Comparison of directly measured $\mathrm{CCN}$ with $\mathrm{CCN}$ modeled from the number-size distribution in the marine boundary layer during ACE 1 at Cape Grim, Tasmania, J. Geophys. Res., 103, 1659716608, 1998.

Chang, R. Y.-W., Liu, P. S. K., Leaitch, W. R., and Abbatt J. P. D.: Comparison between measured and predicted CCN concentrations at Egbert, Ontario, Focus on the organic aerosol fraction at a semi-rural site, Atmos. Environ., 41, 8172-8182, 2007.

Decesari, S., Fuzzi, S., Facchini, M. C., Mircea, M., Emblico, L., Cavalli, F., Maenhaut, W., Chi, X., Schkolnik, G., Falkovich, A., Rudich, Y., Claeys, M., Pashynska, V., Vas, G., Kourtchev, I., Vermeylen, R., Hoffer, A., Andreae, M. O., Tagliavini, E., Moretti, F., and Artaxo, P.: Characterization of the organic composition of aerosols from Rondônia, Brazil, during the LBASMOCC 2002 experiment and its representation through model compounds, Atmos. Chem. Phys., 6, 375-402, doi:10.5194/acp6-375-2006, 2006.

Dinar, E., Taraniuk, I., Graber, E. R., Katsman, S., Moise, T., Anttila, T., Mentel, T. F., and Rudich, Y.: Cloud Condensation Nuclei properties of model and atmospheric HULIS, Atmos. Chem. Phys., 6, 2465-2482, doi:10.5194/acp-6-2465-2006, 2006.

Dusek, U., Covert, D. S., Wiedensohler, A., Neususs, C., Weise, D., and Cantrell, W.: Cloud condensation nuclei spectra derived from size distributions and hygroscopic properties of the aerosol in coastal south-west Portugal during ACE-2, Tellus B, 55, 3553, 2003.

Dusek, U., Frank, G. P., Helas, G. Iinuma, Y., Zeromskiene, K., Gwaze, P., Hennig, T., Massling, A., Schmid, O., Herrmann, H., Wiedensohler, and A., Andreae, M. O.: "Missing" cloud condensation nuclei in peat smoke, Geophys. Res. Lett., 32, L11802, doi:10.1029/2005GL022473, 2005.

Dusek, U., Frank, G. P., Curtius, J., Drewnick, F., Schneider, J., Kürten A., Rose D., Andreae M. O., Borrmann S., and Pöschl U.: Enhanced organic mass fraction and decreased hygroscopicity of cloud condensation nuclei $(\mathrm{CCN})$ during new particle formation events, Geophys. Res. Lett., 37, L03804, doi:10.1029/2009GL040930, 2010.

Ervens, B., Feingold, G., and Kreidenweis, S. M.: Influence of water-soluble organic carbon on cloud drop number concentration, J. Geophys. Res., 110, D18211, doi:10.1029/2004JD005634, 2005.

Ervens, B., Cubison, M., Andrews, E., Feingold, G., Ogren, J. A., Jimenez, J. L., DeCarlo, P., and Nenes, A.: Prediction of cloud condensation nucleus number concentration using measurements of aerosol size distributions and composition and light scattering enhancement due to humidity, J. Geophys. Res., 112, D10S32, doi:10.1029/2006JD007426, 2007.

Facchini, M. C., Mircea, M., Fuzzi, S., and Charlson, R. J.: Cloud albedo enhancement by surface-active organic solutes in growing droplets, Nature, 401, 257-259, 1999.

Facchini, M. C., Decesari, S., Mircea, M., Fuzzi, S., and Loglio, G.: Surface tension of atmospheric wet aerosol and cloud/fog droplets in relation to their organic carbon content and chemical composition, Atmos. Environ., 34, 4853-4857, 2000.

Fors, E. O., Rissler, J., Massling, A., Svenningsson, B., Andreae, M. O., Dusek, U., Frank, G. P., Hoffer, A., Bilde, M., Kiss, G., Janitsek, S., Henning, S., Facchini, M. C., Decesari, S., and Swietlicki, E.: Hygroscopic properties of Amazonian biomass burning and European background HULIS and investigation of their effects on surface tension with two models linking HTDMA to CCNC data, Atmos. Chem. Phys., 10, 5625-5639, doi:10.5194/acp-10-5625-2010, 2010.

Frank, G. P., Dusek, U., and Andreae, M. O.: Technical note: A method for measuring size-resolved $\mathrm{CCN}$ in the atmosphere, Atmos. Chem. Phys. Discuss., 6, 4879-4895, doi:10.5194/acpd-64879-2006, 2006.

Frank, G. P., Dusek, U., and Andreae, M. O.: Technical Note: Characterization of a static thermal-gradient CCN c ounter, Atmos. Chem. Phys., 7, 3071-3080, doi:10.5194/acp-7-3071-2007, 2007.

Gasparini, R., Collins, D. R., Andrews, E., Sheridan, P. J., Ogren, J. A., and Hudson, J. G.: Coupling aerosol size distributions and size-resolved hygroscopicity to predict humidity-dependent optical properties and cloud condensation nuclei spectra, J. Geophys. Res., 111, D05S13, doi:10.1029/2005JD006092, 2006.

Gysel, M., Nyeki, S., Weingartner, E., Baltensperger, U., Giebl, H., Hitzenberger, R., Petzold, A., and Wilson, C. W.: Properties of jet engine combustion particles during the PartEmis experiment: Hygroscopicity at subsaturated conditions, Geophys. Res. Lett., 30, 1566, doi:10.1029/2003GL016896, 2003.

Henning, S., Wex, H., Hennig, T., Kiselev, A., Snider, J. R., Rose, D., Dusek, U., Frank, G. P., Pöschl, U., Kristensson, A., Bilde, M., Tillmann, R., Kiendler-Scharr, A., Mentel, T. F., Walter, S., Schneider, J., Wennrich, C., and Stratmann, F.: Soluble mass, hygroscopic growth, and droplet activation of coated soot particles during LACIS Experiment in November (LExNo), J. Geophys. Res., 115, D11206, doi:10.1029/2009JD012626, 2010.

Hitzenberger, R., Giebl, H., Petzold, A., Gysel, M., Nyeki, S., Weingartner, E., Baltensperger, U., and Wilson, C. W.: Properties of jet engine combustion particles during the PartEmis experiment. Hygroscopic growth at supersaturated conditions, Geophys. Res. Lett., 30, 1779, doi:10.1029/2003GL017294, 2003.

Iinuma, Y., Bruggemann, E., Gnauk, T., Muller, K., Andreae, M. O., Helas, G., Parmar, R., and Herrmann, H.: Source characterization of biomass burning particles: The combustion of selected European conifers, African hardwood, savanna grass, and German and Indonesian peat, J. Geophys. Res., 112, D08209, doi:10.1029/2006JD007120, 2007. 
Kalberer, M., Paulsen, D., Sax, M., Steinbacher, M., Dommen, J., Prevot, A. S. H., Fisseha, R., Weingartner, E., Frankevich, V., Zenobi, R., and Baltensperger, U.: Identification of polymers as major components of atmospheric organic aerosols, Science, 303, 1659-1662, 2004.

Koehler, K. A., Kreidenweis, S. M., DeMott, P. J., Prenni, A. J., Carrico, C. M., Ervens, B., and Feingold, G.: Water activity and activation diameters from hygroscopicity data - Part II: Application to organic species, Atmos. Chem. Phys., 6, 795-809, doi:10.5194/acp-6-795-2006, 2006.

Kreidenweis, S. M., Koehler, K., DeMott, P. J., Prenni, A. J., Carrico, C., and Ervens, B.: Water activity and activation diameters from hygroscopicity data - Part I: Theory and application to inorganic salts, Atmos. Chem. Phys., 5, 1357-1370, doi:10.5194/acp-5-1357-2005, 2005.

Lehmann, K., Massling, A., Tilgner, A., Mertes, S., Galgon, D., and Wiedensohler, A.: Size-resolved soluble volume fractions of submicrometer particles in air masses of different character, Atmos. Environ., 39, 4257-4266, 2005.

Mircea, M., Facchini, M. C., Decesari, S., Cavalli, F., Emblico, L., Fuzzi, S., Vestin, A., Rissler, J., Swietlicki, E., Frank, G., Andreae, M. O., Maenhaut, W., Rudich, Y., and Artaxo, P.: Importance of the organic aerosol fraction for modeling aerosol hygroscopic growth and activation: a case study in the Amazon Basin, Atmos. Chem. Phys., 5, 3111-3126, doi:10.5194/acp-53111-2005, 2005.

Mochida, M. and Kawamura, K.: Hygroscopic properties of levoglucosan and related organic compounds characteristic to biomass burning aerosol particles, J. Geophys. Res., 109, D21202, doi:10.1029/2004JD004962, 2004.

Mochida, M., Kuwata, M., Miyakawa, T., Takegawa, N., Kawamura, K., and Kondo, Y.: Relationship between hygroscopicity and cloud condensation nuclei activity for urban aerosols in Tokyo, J. Geophys. Res., 111, D23204, doi:10.1029/2005JD006980, 2006.

Petters, M. D. and Kreidenweis, S. M.: A single parameter representation of hygroscopic growth and cloud condensation nucleus activity, Atmos. Chem. Phys., 7, 1961-1971, doi:10.5194/acp-71961-2007, 2007.

Petters, M. D., Carrico, C. M., Kreidenweis, S. M., Prenni, A. J., DeMott, P. J., Collett, J. L., and Moosmuller, H.: Cloud condensation nucleation activity of biomass burning aerosol, J. Geophys. Res., 114, D22205, doi:10.1029/2009JD012353, 2009a.

Petters, M. D., Wex, H., Carrico, C. M., Hallbauer, E., Massling, A., McMeeking, G. R., Poulain, L., Wu, Z., Kreidenweis, S. M., and Stratmann, F.: Towards closing the gap between hygroscopic growth and activation for secondary organic aerosol - Part 2: Theoretical approaches, Atmos. Chem. Phys., 9, 3999-4009, doi:10.5194/acp-9-3999-2009, 2009b.

Rissler, J., Swietlicki, E., Zhou, J., Roberts, G., Andreae, M. O., Gatti, L. V., and Artaxo, P.: Physical properties of the submicrometer aerosol over the Amazon rain forest during the wetto-dry season transition - comparison of modeled and measured CCN concentrations, Atmos. Chem. Phys., 4, 2119-2143, doi:10.5194/acp-4-2119-2004, 2004.

Rose, D., Gunthe, S. S., Mikhailov, E., Frank, G. P., Dusek, U., Andreae, M. O., and Pöschl, U.: Calibration and measurement uncertainties of a continuous-flow cloud condensation nuclei counter (DMT-CCNC): $\mathrm{CCN}$ activation of ammonium sulfate and sodium chloride aerosol particles in theory and experiment, Atmos. Chem. Phys., 8, 1153-1179, doi:10.5194/acp-8-11532008, 2008.

Saxena, P. and Hildemann, L. M.: Water-soluble organics in atmospheric particles: A critical review of the literature and application of thermodynamics to identify candidate compounds, J. Atmos. Chem., 24, 57-109, 1996.

Snider, J. R., Wex, H., Rose, D., Kristensson, A., Stratmann, F., Hennig, T., Henning, S., Kiselev, A., Bilde, M., Burkhart, M., Dusek, U., Frank, G. P., Kiendler-Scharr, A., Mentel, T. F., Petters, M. D., Pöschl, U.: Intercomparison of cloud condensation nuclei and hygroscopic fraction measurements: Coated soot particles investigated during the LACIS Experiment in November (LExNo), J. Geophys. Res., 115, D11205, doi:10.1029/2009JD012618, 2010.

Stratmann, F., Bilde, M., Dusek, U., Frank, G. P., Hennig, T., Henning, S., Kiendler-Scharr, A., Kiselev, A., Kristensson, A., Lieberwirth, I., Mentel, T. F., Pöschl, U., Rose, D., Schneider, J., Snider, J. R., Tillmann, R., Walter, S., and Wex, H.: Examination of laboratory-generated coated soot particles: An overview of the LACIS Experiment in November (LExNo) campaign, J. Geophys. Res., 115, D11203, doi:10.1029/2009JD012628, 2010.

Svenningsson, B., Hansson, H., Martinsson, B., Wiedensohler, A., Swietlicki, E., Cederfelt, S., Wendisch, M., Bower, K., Choularton, T., and Colvile, R.: Cloud droplet nucleation scavenging in relation to the size and hygroscopic behaviour of aerosol particles, Atmos. Environ., 31, 2463-2475, 1997.

Svenningsson, B., Rissler, J., Swietlicki, E., Mircea, M., Bilde, M., Facchini, M. C., Decesari, S., Fuzzi, S., Zhou, J., Mnster, J., and Rosenrn, T.: Hygroscopic growth and critical supersaturations for mixed aerosol particles of inorganic and organic compounds of atmospheric relevance, Atmos. Chem. Phys., 6, 1937-1952, doi:10.5194/acp-6-1937-2006, 2006.

Swietlicki, E., Zhou, J. C., Berg, O. H., Martinsson, B. G., Frank, G., Cederfelt, S. I., Dusek, U., Berner, A., Birmili, W., Wiedensohler, A., Yuskiewicz, B., and Bower, K. N.: A closure study of sub-micrometer aerosol particle hygroscopic behaviour, Atmos. Res., 50, 205-240, 1999.

Vestin, A., Rissler, J., Swietlicki, E., Frank, G. P., and Andreae, M. O.: Cloud-nucleating properties of the Amazonian biomass burning aerosol: Cloud condensation nuclei measurements and modeling, J. Geophys. Res., 112, D14201, doi:10.1029/2006JD008104, 2007.

Voutilainen, A., Stratmann, F., and Kaipio, J.: A new data inversion algorithm for DMPS and TDMA measurements, J. Aerosol Sci., 30, 775-776, 1999.

Wex, H., Stratmann, F., Hennig, T., Hartmann, S., Niedermeier, D., Nilsson, E., Ocskay, R., Rose, D., Salma, I., and Ziese, M.: Connecting hygroscopic growth at high humidities to cloud activation for different particle types, Environ. Res. Lett., 3, 035004, doi:10.1088/1748-9326/3/3/035004, 2008a.

Wex, H., Stratmann, F., Topping, D., and McFiggans, G.: The Kelvin versus the Raoult Term in the Kohler Equation, J. Atmos. Sci., 65, 4004-4016, 2008b.

Wex, H., Petters, M. D., Carrico, C. M., Hallbauer, E., Massling, A., McMeeking, G. R., Poulain, L., Wu, Z., Kreidenweis, S. M., and Stratmann, F.: Towards closing the gap between hygroscopic growth and activation for secondary organic aerosol: Part 1 - Evidence from measurements, Atmos. Chem. Phys., 9, 3987-3997, 
doi:10.5194/acp-9-3987-2009, 2009.

Wurzler, S., Herrmann, H., Neusüss, C., Wiedensohler, A., Stratmann, F., Wilck, M., Trautmann, T., Andreae, M. O., Helas, G., Trentmann, J., Langmann, B., Graf, H., and Textor, C.: Impact of vegetation fires on the composition and circulation of the atmosphere: Introduction of the research project EFEU, J. Aerosol Sci. 32, S199-200, 2001.
Zeromskiene, K.: Physical characterization of laboratory produced biomass burning aerosol particles, Ph.D. thesis, Universität Leipzig, Leipzig, Germany, 2005.

Ziese, M., Wex, H., Nilsson, E., Salma, I., Ocskay, R., Hennig, T., Massling, A., and Stratmann, F.: Hygroscopic growth and activation of HULIS particles: experimental data and a new iterative parameterization scheme for complex aerosol particles, Atmos. Chem. Phys., 8, 1855-1866, doi:10.5194/acp-8-1855-2008, 2008. 